\title{
Increased vitamin A intake in children aged 2-5 years through targeted home-gardens in a rural South African community
}

\author{
Mieke Faber ${ }^{1, *}$, Sonja L Venter ${ }^{2}$ and A Spinnler Benadé ${ }^{1}$ \\ ${ }^{1}$ Nutritional Intervention Research Unit, Medical Research Council, PO Box 19070, Tygerberg 7505, South Africa: \\ ${ }^{2}$ Agricultural Research Council, Roodeplaat, South Africa
}

Submitted 23 November 2000: Accepted 15 June 2001

\begin{abstract}
Objectives: To determine vitamin A intake of children aged 2-5 years in a rural South African community one year after the implementation of a home-based food production programme targeting $\beta$-carotene-rich fruits and vegetables.

Design: Dietary intake of children aged $2-5$ years was determined during a crosssectional survey before and one year after the implementation of a home-based food production programme.

Setting: A low socio-economic rural African community, approximately $60 \mathrm{~km}$ northwest of the coastal city of Durban in KwaZulu-Natal, South Africa.

Subjects: Children aged $2-5$ years $(n=100)$; 50 children from households with home-gardens producing $\beta$-carotene fruits and vegetables (project gardens), and 50 children from households without project gardens.

Results: As compared with baseline data, there was a significant increase in vitamin A intake in children from households with project gardens as well as in children from households without project gardens. However, children from households with project gardens had a significantly higher vitamin A intake than children from households without project gardens. The increased vitamin A intake in those children from households without project gardens can be attributed to the availability of butternuts in the local shop (as a result of the project), and because the mothers negotiated with project garden mothers to obtain these fruits and vegetables for their children.

Conclusion: A home-based food production programme targeting $\beta$-carotene-rich fruits and vegetables can lead to an increase in vitamin A intake.
\end{abstract}

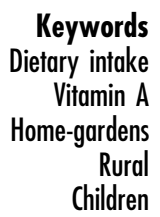

Vitamin A deficiency continues to be a major health problem in developing countries. Vitamin A, in addition to its essential role for vision and eye health, is recognised as a critical factor in child health and survival ${ }^{1}$. Vitamin A can be obtained from supplements, fortified foods or foods naturally rich in vitamin A and provitamin A. Several strategies focusing on supplementation and fortification have been developed to prevent vitamin A deficiency, especially in children. As sustainable approaches catering for the majority of the population should be put in place, food-based approaches should be explored.

Although retinol-rich foods of animal origin are the most effective in improving vitamin A status, these food items are expensive. Yellow/orange fruits and vegetables and dark-green leafy vegetables are rich in provitamin A carotenoids. The human body can convert provitamin A carotenoids into the active form of vitamin A. ProvitaminA-rich fruits and vegetables can provide a valuable contribution to vitamin A intake in communities where alternative dietary sources of vitamin $\mathrm{A}$ are scarce $^{2}$. In
Bangladesh, a large-scale homestead gardening programme promoting the local production of a variety of vegetables throughout the year resulted in an increased availability and consumption of vitamin-A-rich foods ${ }^{3}$.

At a workshop on prevention and control of micronutrient malnutrition through food-based actions of countries of the South Asian Association for Regional Co-operation (SAARC), held in Dhaka, Bangladesh in 1997, it was agreed that it is necessary to look at farms and not pharmacies for the solution of nutritional problems'. It was recognised that safe and nutritious food is a basic human right, and that overall improvement of the diet of the population should be the goal of any food-based action. Benefits of food-based actions include sustainability, cost-effectiveness, income generation and cultural acceptability. In addition, self-reliance and community participation are promoted. An outcome of this workshop was the recommendation that home gardening should be promoted more extensively, selecting fruits and vegetables rich in micronutrients ${ }^{4}$. 
In South Africa one in three pre-school children have serum retinol concentrations below $20 \mu \mathrm{g} \mathrm{dl}^{-1}$, with children from rural areas being affected the worst ${ }^{5}$. The Medical Research Council (MRC) of South Africa, in collaboration with the Agricultural Research Council, implemented a home-based food production programme promoting the production of $\beta$-carotene-rich fruits and vegetables as a means to improve the vitamin A status of a rural community in KwaZulu-Natal known to have a high prevalence of low vitamin status ${ }^{6}$. As community-based food production programmes promoting the cultivation of $\beta$-carotene-rich foods should first of all lead to increased consumption of these food items, the aim of this survey was to determine the effect of a home-based food production programme targeting $\beta$-carotene-rich fruits and vegetables on intake of dietary vitamin $\mathrm{A}$ in children aged $2-5$ years.

\section{Subjects and methods}

\section{Population}

The study population resided in Ndunakazi, a mountainous rural area approximately $60 \mathrm{~km}$ north-west of the coastal city of Durban in KwaZulu-Natal, South Africa.

\section{Baseline survey}

The vitamin A status and dietary intakes of children aged 2-5 years were determined in February 1999 during a cross-sectional survey. The methodology and results of this survey are described elsewhere ${ }^{7}$.

\section{Intervention}

After the baseline survey, a home-based food production programme was implemented. This programme was integrated with a community-based growth monitoring system $^{8}$. Pre-school children in the area attended monthly growth monitoring sessions held at various communitybased growth monitoring points, called Isizinda, which are homes made available by the households on a voluntary basis. As part of the food production programme, a $10 \mathrm{~m} \times 10 \mathrm{~m}$ demonstration garden was established at each Isizinda $(n=9)$. The demonstration gardens were divided into plots the size of a door. These demonstration gardens served as training centres for all mothers attending the growth monitoring sessions. Skills acquired by the mothers were then applied in their home-gardens. Nutrition education at the Isizinda promoted the production of yellow fruits and vegetables and dark-green leafy vegetables at household level, and the daily consumption of these food items was strongly recommended. Information regarding the relationship between vitamin $\mathrm{A}$ and the health of children was conveyed to the mothers in an attempt to explain the importance of these foods and to motivate them to participate. Children were introduced to these vegetables prepared in various ways on growth monitoring days when vegetables from the demonstration garden were being prepared. Beta-carotene-rich vegetables that were seldom or never consumed previously, namely butternut, carrots, an orange-fleshed sweet potato and spinach, were planted in the demonstration gardens and at household level. Each garden also had a paw-paw tree. Cyclic production and crop rotation were promoted to ensure an adequate supply throughout the year. Pumpkin and imifino were already produced locally, and, although promoted, were not planted in the project gardens.

\section{Sampling and etbics}

One year after the implementation of the food production programme, the mothers of a convenience sample of onehundred 2-5-year-old children who attended the Isizinda during February and March 2000 were interviewed. Of these children, 50 children were from households with a project garden (home-gardens producing $\beta$-carotene-rich fruits and vegetables) and 50 children were from households without a project garden. It is estimated that 85-90\% of 2-5-year-old children who were registered at the Isizinda were included in the sample.

For the use of a single 24-hour recall a minimum of 50 children per group is required ${ }^{9}$. It was calculated that 50 children per group would be sufficient to show a significant difference in vitamin A intake of at least $300 \mu \mathrm{g}$ retinol equivalents (RE) at a 5\% significance level with power of $80 \%$.

This study was part of a home-based food production programme targeting $\beta$-carotene-rich fruits and vegetables to address vitamin A deficiencies in children, for which ethical approval was obtained from the Ethics Committee of the South African Medical Research Council. Before implementation of the food production programme, written informed consent was obtained from the mother or guardian after a detailed explanation of the purpose of the study.

\section{Dietary intakes}

The mother or principal caretaker (a member of the household, usually the grandmother of the child, in whose care the child was during the day) was interviewed by a nutrition monitor in her mother language (Zulu).

The 24-hour dietary recall method was used to quantify dietary intake. This method gives valid information on the nutrient intakes of groups, takes about 20-30 minutes of the mother's time, and does not require special skills, e.g. literacy, from the mothers ${ }^{10}$. Fresh food, food models, household utensils and sponge models were used for quantifying and recording food intake. In addition, dry samp (commercially available broken maize) was used to quantify portion sizes of certain food items. The caregiver used the dry samp to indicate the quantity resembling the amount of food consumed by the child, which the nutrition monitor then quantified using a measuring 
cup. Food intake reported in household measures was converted into weight using the MRC Food Quantities Manual $^{11}$. The SAS software package was used to convert food intake to macro- and micronutrients, using the $M R C$ Food Composition Tables ${ }^{12}$ as food database.

\section{Sources of $\beta$-carotene-rich fruits and vegetables}

The sources of various $\beta$-carotene-rich fruits and vegetables for the month prior to the survey were determined by questionnaire. The questionnaire was developed through observation and group discussions, and was pre-tested at the Isizinda.

\section{Data analysis}

The data were analysed using univariate and frequency analysis, and analysis of variance using the SAS statistical package - release 6.12 edition, 1988 (SAS Institute Inc., Cary, NC). Quantified dietary intakes are summarised by the medians and 25th and 75th percentiles (Q1-Q3; interquartile range), since some of the data had skewed distributions. The difference in total nutrient intakes between the two groups was tested for using analysis of variance. Beta-carotene-rich fruits and vegetables reported during the 24-hour recall period were identified, and the micronutrients supplied by these fruits and vegetables (mango, peach, paw-paw, imifino (a local term for a collection of wild-growing dark-green leafy vegetables resembling spinach), spinach, pumpkin, butternut, sweet potato and carrots) were calculated.

\section{Results}

\section{4-bour recall}

Total energy intake and energy distribution of the macronutrients for children aged 2-5 years at baseline and one year after implementation are given in Table 1. The food production programme did not have a major impact on macronutrient intake.

Micronutrient intakes are summarised in Table 2. Children from households with a project garden had significantly $(P<0.05)$ higher dietary intakes for vitamin A, riboflavin, vitamin $\mathrm{B}_{6}$ and ascorbic acid, and a tendency $(P<0.1)$ towards a higher calcium intake, as compared with children from households without a project garden. Micronutrients supplied by the $\beta$ carotene-rich fruits and vegetables are also listed in Table 2. For children from households with project gardens, these fruits and vegetables contributed more than $50 \%$ of total intake for calcium, iron and vitamin A, and between 25 and $50 \%$ of total intake for magnesium, riboflavin and vitamin $\mathrm{C}$.

\section{Sources of $\beta$-carotene-rich fruits and vegetables}

The sources from which $\beta$-carotene-rich fruits and vegetables were obtained during the month prior to the survey are indicated in Table 3 . The main source for imifino and pumpkin (foods produced in the area before implementation of the food production programme) for both groups was the family's own home-garden. For children from households with project gardens, these gardens were the main source for butternuts, carrots, spinach and orange-fleshed sweet potato. For children from households without project gardens, these fruits and vegetables were mostly bought (mainly butternut and carrots) or obtained from family, friends and neighbours (especially paw-paw). Peaches and mangoes were mainly bought in both groups.

\section{Discussion}

The baseline survey showed that children in this rural area consumed a cereal-based diet, with staple foods being phutu (a food traditional to black South Africans comprising maize meal made into a stiff porridge), bread and rice. Legumes, mostly beans, formed an integral part of the diet. Food intake was limited to 44 food items. The diet lacked variety, predisposing the children to low micronutrient intakes. Low dietary intakes of foods rich in vitamin $\mathrm{A}$ and $\beta$-carotene were reflected in low serum retinol levels, with half of the children presenting with serum retinol levels ${ }^{7}$ below $20 \mu \mathrm{g} \mathrm{dl}^{-1}$.

One year after the implementation of a home-based food production programme, dietary vitamin A intake increased significantly in children from households with a

Table 1 The median and interquartile range (Q1-Q3) for total energy, energy distribution of macronutrients of rural South African children aged $2-5$ years

\begin{tabular}{lcccc}
\hline & & & \multicolumn{2}{c}{ One year after implementation } \\
\cline { 3 - 4 } & & $\begin{array}{c}\text { Baseline } \\
(n=154)\end{array}$ & $\begin{array}{c}\text { With garden } \\
(n=50)\end{array}$ & $\begin{array}{c}\text { Without garden } \\
(n=50)\end{array}$ \\
\hline Energy (kJ) & Median & 5085 & 5200 & 5406 \\
Protein (\% of energy) & Q1-Q3 & $3988-6149$ & $4593-6005$ & $4372-6758$ \\
Total fat (\% of energy) & Median & 10.9 & 10.8 & 10.6 \\
\multirow{2}{*}{ Carbohydrate (\% of energy) } & Q1-Q3 & $9.0-12.1$ & $9.4-11.9$ & $9.1-12.4$ \\
& Median & 27.1 & 24.5 & 24.1 \\
& Q1-Q3 & $20.2-33.6$ & $21.4-29.0$ & $18.9-27.9$ \\
& Median & 67.0 & 70.6 & 71.7 \\
\hline
\end{tabular}


Table 2 Micronutrient intakes in children aged 2-5 years as determined by a 24-hour dietary recall at baseline and one year after the implementation of a home-based food production programme. Values are given as the median and the interquartile range (Q1-Q3)

\begin{tabular}{|c|c|c|c|c|c|c|c|}
\hline \multirow[b]{3}{*}{ Nutrient } & & \multirow[b]{3}{*}{$\begin{array}{l}\text { Baseline } \\
(n=154)\end{array}$} & \multicolumn{5}{|c|}{ One year after implementation } \\
\hline & & & \multicolumn{3}{|c|}{ Total intake } & \multicolumn{2}{|c|}{$\begin{array}{l}\text { Intake from } \beta \text {-carotene-rich } \\
\text { fruits and vegetables }\end{array}$} \\
\hline & & & $\begin{array}{l}\text { With garden } \\
\quad(n=50)\end{array}$ & $\begin{array}{l}\text { Without garden } \\
\qquad(n=50)\end{array}$ & $P$-value* & $\begin{array}{l}\text { With garden } \\
\quad(n=50)\end{array}$ & $\begin{array}{l}\text { Without garden } \\
\quad(n=50)\end{array}$ \\
\hline \multirow[t]{2}{*}{ Calcium (mg) } & Median & 217 & 451 & 280 & 0.0774 & 253 & 26 \\
\hline & Q1-Q3 & $165-333$ & $224-531$ & $202-481$ & & $22-381$ & $2-261$ \\
\hline \multirow[t]{2}{*}{ Iron (mg) } & Median & 6.4 & 13.5 & 7.8 & 0.1453 & 8.0 & 0.5 \\
\hline & Q1-Q3 & $4.2-9.2$ & $5.9-16.2$ & $5.2-14.3$ & & $0.5-11.3$ & $0.0-8.3$ \\
\hline \multirow{2}{*}{ Magnesium (mg) } & Median & 218 & 296 & 244 & 0.5372 & 108 & 15 \\
\hline & Q1-Q3 & $168-300$ & $204-342$ & $189-345$ & & $14-163$ & $1-109$ \\
\hline \multirow[t]{2}{*}{ Zinc (mg) } & Median & 4.0 & 4.6 & 4.7 & 0.7869 & 1.0 & 0.46 \\
\hline & Q1-Q3 & $3.0-5.2$ & $3.9-5.7$ & $3.9-5.9$ & & $0.4-1.6$ & $0.04-0.88$ \\
\hline \multirow[t]{2}{*}{ Vitamin A (RE) } & Median & 150 & 1133 & 640 & 0.0004 & 998 & 548 \\
\hline & Q1-Q3 & $56-579$ & $636-1765$ & $372-1039$ & & $548-1604$ & $53-707$ \\
\hline \multirow[t]{2}{*}{ Thiamine (mg) } & Median & 0.75 & 0.85 & 0.83 & 0.9421 & 0.14 & 0.11 \\
\hline & Q1-Q3 & $0.54-0.99$ & $0.74-1.02$ & $0.62-1.06$ & & $0.09-0.23$ & $0.01-0.15$ \\
\hline \multirow[t]{2}{*}{ Riboflavin (mg) } & Median & 0.43 & 0.91 & 0.58 & 0.0001 & 0.42 & 0.03 \\
\hline & Q1-Q3 & $0.29-0.64$ & $0.63-1.48$ & $0.42-0.83$ & & $0.04-0.59$ & $0.0-0.41$ \\
\hline \multirow[t]{2}{*}{ Niacin (mg) } & Median & 4.07 & 5.17 & 5.25 & 0.8921 & 1.06 & 0.54 \\
\hline & Q1-Q3 & $3.15-5.44$ & $4.13-6.33$ & $4.05-6.22$ & & $0.46-1.62$ & $0.10-1.17$ \\
\hline \multirow[t]{2}{*}{ Vitamin $B_{6}(\mathrm{mg})$} & Median & 0.75 & 0.71 & 0.62 & 0.0294 & 0.08 & 0 \\
\hline & Q1-Q3 & $0.54-0.94$ & $0.52-1.04$ & $0.44-0.80$ & & $0.01-0.14$ & $0-0$ \\
\hline \multirow[t]{2}{*}{ Vitamin $B_{12}(\mu \mathrm{g})$} & Median & 0 & 0.63 & 0.15 & 0.6795 & 0 & 0 \\
\hline & Q1-Q3 & $0-0.10$ & $0-1.18$ & $0-0.95$ & & $0-0$ & $0-0$ \\
\hline \multirow[t]{2}{*}{ Folic acid $(\mu \mathrm{g})$} & Median & 218 & 193 & 189 & 0.7858 & 31 & 0 \\
\hline & Q1-Q3 & $124-332$ & $133-290$ & $116-328$ & & $4-44$ & $0-39$ \\
\hline \multirow[t]{2}{*}{ Vitamin C (mg) } & Median & 43.1 & 61.6 & 31.8 & 0.0235 & 17 & 12 \\
\hline & Q1-Q3 & $16.3-87.5$ & $29.8-104.1$ & $19.5-76.8$ & & $9-29$ & $1-16$ \\
\hline
\end{tabular}

* Difference between those children from households with home-gardens producing $\beta$-carotene-rich fruits and vegetables and those children from households without home-gardens producing $\beta$-carotene-rich fruits and vegetables, as determined by analysis of variance.

Table 3 Sources of $\beta$-carotene-rich fruits and vegetables

\begin{tabular}{|c|c|c|c|c|c|}
\hline & Not eaten* & Bought & Own garden & Community garden & Neighbours, family, friends \\
\hline \multicolumn{6}{|l|}{ Butternut } \\
\hline With gardens & 2 & 4 & 86 & 2 & 6 \\
\hline Without gardens & 37 & 43 & 4 & 0 & 16 \\
\hline \multicolumn{6}{|l|}{ Carrots } \\
\hline With gardens & 30 & 18 & 48 & 0 & 4 \\
\hline Without gardens & 78 & 16 & 2 & 0 & 4 \\
\hline \multicolumn{6}{|l|}{ Imifino } \\
\hline With gardens & 4 & 2 & 94 & 0 & 0 \\
\hline Without gardens & 2 & 0 & 80 & 6 & 12 \\
\hline \multicolumn{6}{|l|}{ Pumpkin } \\
\hline With gardens & 51 & 0 & 47 & 0 & 2 \\
\hline Without gardens & 20 & 0 & 72 & 4 & 4 \\
\hline \multicolumn{6}{|l|}{ Spinach } \\
\hline With gardens & 70 & 2 & 26 & 0 & 2 \\
\hline Without gardens & 98 & 0 & 0 & 0 & 2 \\
\hline \multicolumn{6}{|l|}{ Sweet potato } \\
\hline With gardens & 62 & 0 & 20 & 0 & 18 \\
\hline Without gardens & 96 & 0 & 0 & 0 & 4 \\
\hline \multicolumn{6}{|l|}{ Mango } \\
\hline With gardens & 66 & 30 & 4 & 0 & 0 \\
\hline Without gardens & 86 & 14 & 0 & 0 & 0 \\
\hline \multicolumn{6}{|l|}{ Paw-paw } \\
\hline With gardens & 36 & 4 & 18 & 0 & 42 \\
\hline Without gardens & 80 & 0 & 2 & 0 & 18 \\
\hline \multicolumn{6}{|l|}{ Peach } \\
\hline With gardens & 64 & 34 & 0 & 0 & 2 \\
\hline Without gardens & 80 & 20 & 0 & 0 & 0 \\
\hline
\end{tabular}

* Not eaten during the month prior to the survey. 
project garden, and to a lesser extent in children from households without a project garden. From Table 2 it can be calculated that at least $85 \%$ of the vitamin A intake in both groups originated from $\beta$-carotene-rich fruits and vegetables. The increased intake of vitamin $\mathrm{A}$ in children from households without a project garden was a result of an increased awareness in the community, created not only by the visibility of the demonstration and project gardens, but also by a nutrition education programme that was linked to the food production programme and run at the Isizinda.

Because of this newly created awareness and because of the popularity of butternuts within the community, the shop owner saw an opportunity: whereas butternuts were previously not available, butternuts are now freely available in the local shops. The availability of butternuts in the local shops is valued as a significant outcome of this project as this could potentially impact on the dietary intakes of the entire population.

Although not all households participated in the project (participation was voluntary), all of the mothers/caregivers of the pre-school children attending the Isizinda received the nutrition education, and all children received cooked vegetables from the demonstration garden on the day of growth monitoring. Although some mothers opted not to have a project garden, many of them realised the nutritional benefits of these fruits and vegetables and negotiated with family, friends or neighbours to obtain some of these fruits and vegetables for their children.

Another factor that could have influenced the vitamin A intake in both groups is an increased intake of imifino and pumpkin. It was previously shown that although these food items are produced locally, the quantity grown and eaten was low ${ }^{13}$. The awareness created resulted in an increased intake - both imifino and pumpkin were reported during the 24-hour recall period for approximately half of the children from households without a project garden.

It could be argued that a community far away should be used as control area to prevent awareness having an influence on dietary intakes. It is not always easy to define an appropriate control group because it is difficult to determine the exact boundaries between communities that are influenced by a programme and those that are not. If a control community is chosen far away from the intervention community other factors could lead to a difference, or changes within the experimental community that could influence the outcome of a study will not be picked up. Although the vitamin A intake of children from households without a project garden was affected by the awareness created by the project through the availability of butternuts in the local shops, negotiations between households and increased consumption of locally grown imifino and pumpkin, these factors will also affect children from households with project gardens. This is clearly seen by the fact that imifino was reported during the 24 -hour recall period for $64 \%$ of children from households with a project garden, and furthermore that $42 \%$ of these households with project gardens obtained paw-paws from family, friends or neighbours. However, the significantly higher vitamin A intake of children from households with a project garden, as compared with those without a project garden, shows that home-gardens targeting $\beta$-carotene-rich fruits and vegetables are an effective way to improve the vitamin A content of the diet of children in a rural area.

There are several indications that an increased vitamin A intake through fruits and vegetables will result in an improved vitamin A status. A positive relationship between the consumption of carotene-rich fruits, such as mango, and vitamin A status has been reported ${ }^{14}$. In Japanese men, a positive association was found between changes in the intake frequency of green and yellow vegetables and changes in serum $\beta$-carotene levels ${ }^{15}$. Although de Pee et al. showed that dark-green leafy vegetables had no effect on vitamin A status because of their low bioavailability ${ }^{16}$, among 2-15-year-old children in Bangladesh serum vitamin A levels were strongly associated with food intake, the most significant association being with consumption of dark-green leafy vegetables ${ }^{17}$. In children aged 2-6 years consumption of green leafy vegetables with added fat resulted in improved vitamin A status ${ }^{18,19}$.

In Vietnam a community nutrition project focusing on household food production, especially carotene-rich fruits and vegetables, and nutrition education resulted in a significant reduction in the incidence and severity of acute respiratory infections, and the incidence of diarrhoeal disease in young children ${ }^{20}$.

In addition to the health benefits of increased intake of $\beta$-carotene-rich fruits and vegetables, the home-gardens introduced more variety in the diets of these children, specifically regarding fruit and vegetable intake. Before the onset of the project, vegetables consumed were mainly tomatoes, cabbage, pumpkin and imifino. Vegetables introduced by the project were butternuts, carrots, spinach and an orange-fleshed sweet potato.

The main objective of the gardens was obtained; namely, a significant increase in vitamin A intake. The gardens had an additional benefit in that the intake of various other nutrients also increased. The trend for children from households with a project garden to have a higher calcium intake than children from households without a project garden can be ascribed to the increased intake of imifino. Keeping in mind that the overall calcium intake of these children was very low, this is a positive effect.

In addition to the health benefits, the production of these food items at household level has the potential for income generation and therefore social uplifting of these households and eventually the community as a whole.

A community-based food production programme 
targeting $\beta$-carotene-rich fruits and vegetables resulted in a significant increase in vitamin $\mathrm{A}$ intake, in children from households with project gardens as well as in children from households without project gardens. Vitamin A intake was significantly higher in those children from households with project gardens.

\section{Acknowledgements}

The work was funded by the Thrasher Research Fund. We thank Mr Michael Phungula and our team of nutrition monitors for their invaluable support and dedication to the study, and the children and caregivers who participated in the study.

\section{References}

1 World Health Organization (WHO)/United Nations Children's Fund (UNICEF). Indicators for Assessing Vitamin A Deficiency and Their Application in Monitoring and Evaluating Intervention Programmes. Review version. Geneva: WHO, 1994.

2 Bloem MW, Huq N, Gorstein J, Burger S, Kahn T, Islam N, Baker S, Davidson F. Production of fruits and vegetables at the homestead is an important source of vitamin A among women in rural Bangladesh. Eur. J. Clin. Nutr. 1996; 50(Suppl. 3): S62-7.

3 Talukder A, Kiess L, Huq N, de Pee S, Darnton-Hill I, Bloem MW. Increasing the production and consumption of vitamin A-rich fruits and vegetables: lessons learned in taking the Bangladesh homestead gardening programme to a national scale. Food Nutr. Bull. 2000; 21: 165-72.

4 Hussain A. Preventing and controlling micronutrient malnutrition through food-based actions in South Asian countries. Food Nutr. Agric. 1998; 22: 63-5.

5 South African Vitamin A Consultative Group (SAVACG). Anthropometric, vitamin A, iron, and immunisation coverage status in children aged 6-71 months in South Africa. $S$. Afr. Med. J. 1994; 86: 354-7.

6 Oelofse A, Faber M, Benadé JG, Benadé AJS, Kenoyer DG. The nutritional status of a rural community in KwaZuluNatal, South Africa: the Ndunakazi project. Centr. Afr. J. Med. 1999; 45: 14-9.

7 Faber M, Jogessar VB, Benadé AJS. Nutritional status and dietary intakes of children aged 2-5 years and their caregivers in a rural South African community. Int. J. Food Sci. Nutr. 2001 [in press].

8 Faber M, Oelofse A, Benadé AJS. A model for a communitybased growth monitoring system. Afr. J. Health Sci. 1998; 5: $72-8$.

9 Young CM, Hagan GC, Tucker RE, et al. A comparison of dietary study methods. II. Dietary history versus seven-day record versus 24-hour recall. J. Am. Diet. Assoc. 1952; 28: 218-21.

10 Cameron ME, Van Staveren WA. Manual on Methodology for Food Consumption Studies. New York: Oxford University Press, 1988; 84.

11 Langenhoven ML, Conradie PJ, Wolmarans P, Faber M. MRC Food Quantities Manual, 1991, 2nd ed. Parow: Medical Research Council, 1991.

12 Langenhoven ML, Kruger M, Gouws E, Faber M. MRC Food Composition Tables, 1991, 3rd ed. Parow: Medical Research Council, 1991.

13 Faber M, Smuts CM, Benadé AJS. Dietary intake of primary school children in relation to food production in a rural area in KwaZulu-Natal, South Africa. Int. J. Food Sci. Nutr. 1999; 50: $57-64$.

14 Carlier C, Etchepare M, Ceccon JF, Mourey MS, AmédéeManesme O. Efficacy of massive oral doses of retinyl palmitate and mango (Mangigera indica L.) consumption to correct an existing vitamin A deficiency in Senegalese children. Br. J. Nutr. 1992; 68: 529-40.

15 Suzuki S, Sasaki R, Ito Y, Hamajima N, Shibata A, Tamakoshi A, Otani M, Aoki K. Changes in serum concentrations of $\beta$ carotene and changes in the dietary intake frequency of green-yellow vegetables among healthy male inhabitants of Japan. Jpn. J. Cancer Res. 1990; 81: 463-69.

16 De Pee S, West CE, Muhilal Karyadi D, Hautvast JGAJ. Lack of improvement in vitamin A status with increased consumption of dark-green leafy vegetables. Lancet 1995; 346: $75-81$.

17 Hussain A, Kvåle G. Serum vitamin A in relation to socioeconomic, demographic and dietary characteristics in Bangladeshi children. Acta Paediatr. 1996; 85: 971-6.

18 Jayarajan P, Reddy V, Mohanram M. Effect of dietary fat on absorption of $\beta$-carotene from green leafy vegetables in children. Ind. J. Med. Res. 1980; 71: 53-6.

19 Takyi EEK. Children's consumption of dark green, leafy vegetables with added fat enhances serum retinol. J. Nutr. 1999; 129: 1549-54.

20 English RM, Badcock JC, Giay T, Ngu T, Waters A-M, Bennet SA. Effect of nutrition improvement project on morbidity from infectious diseases in preschool children in Vietnam: comparison with control commune. Br. Med. J. 1997; 315: $1122-5$. 